\title{
Astaxanthin degradation and lipid oxidation of Pacific white shrimp oil: kinetics study and stability as affected by storage conditions
}

\author{
Sirima Takeungwongtrakul $\cdot$ Soottawat Benjakul
}

Received: 7 September 2015/ Accepted: 22 December 2015/Published online: 23 February 2016

(C) The Author(s) 2016. This article is published with open access at Springerlink.com

\begin{abstract}
The kinetics of astaxanthin degradation and lipid oxidation in shrimp oil from hepatopancreas of Pacific white shrimp (Litopenaeus vannamei) as affected by storage temperature were studied. When shrimp oil was incubated at different temperatures $\left(4,30,45\right.$ and $\left.60^{\circ} \mathrm{C}\right)$ for $16 \mathrm{~h}$, the rate constants $(k)$ of astaxanthin degradation and lipid oxidation in shrimp oil increased with increasing temperatures $(p<0.05)$. Thus, astaxanthin degradation and lipid oxidation in shrimp oil were augmented at high temperature. When shrimp oils with different storage conditions (illumination, oxygen availability and temperature) were stored for up to 40 days, astaxanthin contents in all samples decreased throughout storage $(p<0.05)$. All factors were able to enhance astaxanthin degradation during 40 days of storage. With increasing storage time, the progressive formation of primary and secondary oxidation products were found in all samples as evidenced by the increases in both peroxide values (PV) and thiobarbituric acid reactive substances (TBARS) $(p<0.05)$. Light, air and temperatures therefore had the marked effect on astaxanthin degradation and lipid oxidation in shrimp oils during the extended storage.
\end{abstract}

Keywords Shrimp oil · Astaxanthin degradation · Lipid oxidation · Illumination · Oxygen availability · Temperature

\section{Introduction}

Pacific white shrimp (Litopenaeus vannamei) is an important commercial species primarily cultured with high market value. In 2013, the world production of 3,314,447 tons was reported (FAO 2015). Hepatopancreas, a byproduct generated from the manufacturing of hepatopancreas-free whole shrimp, is approximately 5-7 \% of the total weight. It is the excellent source of oils with high polyunsaturated fatty acids (PUFA) $(37.42 \mathrm{~g} / 100 \mathrm{~g}$ oil) and astaxanthin (2.02 mg/g oil), which are well known for their health benefits (Takeungwongtrakul et al. 2012). Nevertheless, astaxanthin and oil are susceptible to oxidation due to their highly unsaturated structures. Environmental factors such as oxygen concentration, storage temperature and light also influence the oxidation of astaxanthin and oil (Borsarelli and Mercadante 2010; Pristouri et al. 2010). Oxidation taken place

\footnotetext{
S. Takeungwongtrakul

Department of Agricultural Education, Faculty of Industrial Education, King Mongkut's Institute of Technology Ladkrabang, Ladkrabang, Bangkok 10520, Thailand

S. Benjakul $(\bowtie)$

Department of Food Technology, Faculty of Agro-Industry, Prince of Songkla University, Hat Yai, Songkhla 90112,

Thailand

e-mail: soottawat.b@psu.ac.th
} 
during processing, storage and distribution reduces the nutritive value and affects the quality of astaxanthin and oil (Nawar 1996). The assurance of stability and quality of oil rich in both astaxanthin and PUFAs is of importance and necessity (Mancebo-Campos et al. 2008).

Better understanding of astaxanthin degradation and lipid oxidation kinetics in oils as well as factors involved in those alterations could help in minimizing the loss in quality of oil rich in astaxanthin. Astaxanthin degradation and lipid oxidation of the oil mostly depend on the storage temperature and storage time (Aidos et al. 2002), and are associated with the limited shelf-life. Temperature is likely to be the most influential factor in enhancing the oxidation and hydroperoxide decomposition intensely proceeds with increasing temperature (Erkan et al. 2009). Kinetic data can be used to distinguish the origin of oil or to characterize the differences or similarities in the oils (Tan et al. 2001). These data are very useful for predicting the oxidative stability of oils under various heat processing, storage and distribution conditions (Huang and Sathivel 2008; Tan et al. 2001). Nevertheless, scanty information regarding the kinetics of astaxanthin degradation and lipid oxidation in shrimp oil and the effects of environmental factors on oxidative stability of shrimp oil has been reported. Hence, the objectives of the present study were to determine the kinetics of astaxanthin degradation and lipid oxidation of shrimp oil as a function of temperature and to study the oxidative stability of shrimp oil as affected by different storage conditions.

\section{Materials and methods}

\section{Chemicals}

Ammonium thiocyanate was purchased from Sigma (St. Louis. MO, USA). Trichloroacetic acid, anhydrous sodium sulfate, isooctane, ethanol and ferrous chloride were obtained from Merck (Darmstadt, Germany). Cumene hydroperoxide, 2-thiobarbituric acid and 1,1,3,3-tetramethoxypropane were procured from Fluka (Buchs, Switzerland). Isopropanol, hexane, chloroform, petroleum ether, hydrochloric acid and ammonium thiocyanate were purchased from Lab-Scan (Bangkok, Thailand).

\section{Collection of hepatopancreas from Pacific white shrimp}

Hepatopancreas of Pacific white shrimp (Litopenaeus vannamei) with the size of 50-60 shrimp/kg was obtained from the Sea wealth frozen food Co., Ltd., Songkhla province, Thailand during November and December, 2014. For each lot, pooled hepatopancreas $(3-5 \mathrm{~kg})$, used as the composite sample, was placed in polyethylene bag. The bag was imbedded in a polystyrene box containing ice with a sample/ice ratio of 1:2 (w/ w) and transported to the Department of Food Technology, Prince of Songkla University, Hat Yai, Songkhla within approximately $2 \mathrm{~h}$. The sample was stored at $-18{ }^{\circ} \mathrm{C}$ until use, but the storage time was not longer than 1 month. Prior to oil extraction, hepatopancreas was ground in the presence of liquid nitrogen using a blender (Phillips, Guangzhou, China) for $30 \mathrm{~s}$.

Extraction of oils from hepatopancreas

Oil was extracted from hepatopancreas following the method of Takeungwongtrakul et al. (2014). The prepared hepatopancreas $(20 \mathrm{~g})$ was homogenized with $90 \mathrm{ml}$ of cold solvent mixtures (isopropanol: hexane, 50: 50, v/v) $\left(4^{\circ} \mathrm{C}\right)$ at the speed of $9500 \mathrm{rpm}$ using an IKA Labortechnik homogenizer (Selangor, Malaysia) for 2 min at $4{ }^{\circ} \mathrm{C}$. The extract was filtered using a Whatman filter paper No.4 (Whatman International Ltd., Maidstone, England). The residue was extracted with cold solvent mixtures for another two times. The hexane fraction was pooled and repeatedly washed with an equal quantity of $1 \% \mathrm{NaCl}$ in order to separate the phases and remove traces of polar solvents. Hexane fraction (approximately $135 \mathrm{ml}$ ) was then added with $2-5 \mathrm{~g}$ anhydrous sodium sulfate, shaken very well, and decanted into a round-bottom flask through a Whatman No. 4 filter paper. The solvent was evaporated at $40{ }^{\circ} \mathrm{C}$ using an EYELA rotary evaporator N-1000 (Tokyo Rikakikai, Co. Ltd, Tokyo, Japan) and the residual solvent was removed by nitrogen flushing. 
Effect of temperatures on astaxanthin degradation and lipid oxidation of shrimp oil

Shrimp oil ( $15 \mathrm{~g})$ was transferred into the amber bottle and capped. The bottles containing shrimp oil were placed in the water bath at different temperatures $\left(30,45\right.$ and $\left.60{ }^{\circ} \mathrm{C}\right)$. The samples were also stored at $4{ }^{\circ} \mathrm{C}$. The oil samples were taken randomly at $0,2,4,8$ and $16 \mathrm{~h}$ and analyzed for astaxanthin content and peroxide value (PV). Kinetics for astaxanthin degradation and lipid oxidation were studied.

\section{Analyses}

Measurement of astaxanthin content

Astaxanthin content in the oil samples was determined according to the method of Saito and Regier (1971) with a slight modification. Oil $(30 \mathrm{mg})$ was mixed with $10 \mathrm{ml}$ of petroleum ether and the mixture was allowed to stand for $30 \mathrm{~min}$. The absorbance of oil, appropriately diluted, was measured at $468 \mathrm{~nm}$ using a UV-1601 spectrophotometer (Shimadzu, Kyoto, Japan). The concentration $(C)$ of astaxanthin in the sample was calculated using the equation given by Saito and Regier (1971) with a slight modification as follows:

$$
C(\mu \mathrm{g} / \mathrm{g} \text { lipid })=\frac{A_{468} \times \text { volume of solution } \times \text { dilution factor }}{0.2 \times \text { weight of sample used in gram }}
$$

where 0.2 is the $A_{468}$ of $1 \mu \mathrm{g} / \mathrm{ml}$ standard astaxanthin, 10 is the volume of solution and 1 is the dilution factor of solution.

Peroxide value (PV)

PV was determined using the ferric thiocyanate method (Chaijan et al. 2006). To $50 \mu$ of oil sample (tenfold dilution using $75 \%$ ethanol, v/v), $2.35 \mathrm{ml}$ of $75 \%$ ethanol (v/v), $50 \mu \mathrm{l}$ of $30 \%$ ammonium thiocyanate (w/v) and $50 \mu \mathrm{l}$ of $20 \mathrm{mM}$ ferrous chloride solution in $3.5 \% \mathrm{HCl}(\mathrm{w} / \mathrm{v})$ were added and mixed thoroughly. After $3 \mathrm{~min}$, the absorbance of the colored solution was read at $500 \mathrm{~nm}$ using a spectrophotometer. Blank was prepared in the same manner, except the distilled water was used instead of ferrous chloride. PV was calculated after blank subtraction. A standard curve was prepared using cumene hydroperoxide with the concentration range of $0.5-2 \mathrm{ppm}$. PV was expressed as $\mathrm{mg}$ cumene hydroperoxide/ $\mathrm{kg}$ oils.

Kinetic studies

\section{Astaxanthin degradation rate of shrimp oil}

The first-order model was used to describe the astaxanthin degradation kinetics as described by Eq. 1 (Niamnuy et al. 2008):

$$
\ln \left(C / C^{\prime}\right)=-k t
$$

where $C^{\prime}$ is the initial astaxanthin concentration $(\mathrm{mg} / \mathrm{kg}$ oil); $C$ is the astaxanthin concentration $(\mathrm{mg} / \mathrm{kg}$ oil) at time $t$; $k$ is the degradation rate constant $\left(\mathrm{h}^{-1}\right)$; $\mathrm{t}$ is the exposure time (h). A plot of $\ln \left(C / C^{\prime}\right)$ versus $t$ was constructed at different temperatures $\left(4,30,45\right.$ and $\left.60^{\circ} \mathrm{C}\right)$ to determine the $k$ values and the correlation coefficients. The slope of the straight line and the correlation coefficient were obtained from the trend line of the plot. The $k$ values of shrimp oil were obtained from the slope of the plot.

The effect of temperature on the degradation rate was described using the Arrhenius relationship as shown in Eq. 2 (Pu and Sathivel 2011). 


$$
\ln k=-E_{\mathrm{a}} / R T+\ln k_{\infty}
$$

where $k$ is the reaction rate constant; $k_{\infty}$ is the frequency factor; $R$ is the universal gas constant $(8.3145 \mathrm{~J} / \mathrm{mol} \mathrm{K}) ; \mathrm{T}$ is the absolute temperature $(K) ; E_{\mathrm{a}}$ is the activation energy $(\mathrm{J} / \mathrm{mol})$. The resulting $k$ values from the first order model ( $\ln k$ ) versus $1 / \mathrm{T}$ (i.e., 1/absolute temperature) were plotted and the activation energy $\left(E_{\mathrm{a}}\right)$ was obtained for astaxanthin degradation using the Arrhenius model. The magnitude of $E_{\mathrm{a}}$ was calculated as the slope of the trend line multiplied by the universal gas constant. The half-life $\left(t_{1 / 2}\right)$ was calculated using Eq. 3.

$$
t_{1 / 2}=\ln 2 / k
$$

\section{Lipid oxidation rate of shrimp oil}

A plot of PV versus time was constructed at various temperatures $\left(4,30,45\right.$ and $\left.60{ }^{\circ} \mathrm{C}\right)$. The resulting straight line yielded the magnitude of the oxidation rate $(\mathrm{mg} / \mathrm{kg}$ oil $/ \mathrm{h})$ at the corresponding temperature. The effect of temperature on the oxidation rate was described using the Arrhenius relationship as shown in Eq. 2. The slope of the straight line was obtained from the trend line of the plot. The magnitude of $E_{\mathrm{a}}$ was calculated as the slope of the trend line multiplied by the universal gas constant ( $\mathrm{Pu}$ and Sathivel 2011).

Oxidative stability of shrimp oils as affected by different storage conditions

The oil $(15 \mathrm{ml})$ was transferred into the bottles, capped and stored under different atmospheres (nitrogen and air). To prepare sample with nitrogen atmosphere, the shrimp oil was flushed for 3 min with nitrogen gas. The bottles containing shrimp oil were placed under different illumination conditions (dark and light) at two temperatures ( 4 and $30^{\circ} \mathrm{C}$ ). Darkness was achieved by using amber glass bottles covered with aluminum foil. Another sample was exposed to light with an intensity of approximately $600 \mathrm{~lx}$.

All samples $(2 \times 2 \times 2$ samples $)$ were randomly taken at day 0, 10, 20, 30 and 40 for the determination of astaxanthin content and PV as previously described. Additionally, thiobarbituric acid reactive substances (TBARS) were also determined.

TBARS were determined as described by Buege and Aust (1978). Oil sample (0.5 g) was mixed with $2.5 \mathrm{ml}$ of a solution containing $0.375 \%$ thiobarbituric acid (w/v), $15 \%$ trichloroacetic acid (w/v) and $0.25 \mathrm{M}$ $\mathrm{HCl}$. The mixture was heated in a boiling water $\left(95-100{ }^{\circ} \mathrm{C}\right)$ for $10 \mathrm{~min}$ to develop a pink color, cooled with running tap water and centrifuged at $3600 \times g$ at $25^{\circ} \mathrm{C}$ for $20 \mathrm{~min}$ using a centrifuge (Beckman Coulter, Avanti J-E Centrifuge, Fullerton, CA, USA). The absorbance of the supernatant was measured at $532 \mathrm{~nm}$ using a spectrophotometer. A standard curve was prepared using 1,1,3,3-tetramethoxypropane at the concentrations ranging from 0 to $6 \mathrm{ppm}$. TBARS were calculated and expressed as mg malonaldehyde/ $\mathrm{kg}$ oils.

Statistical analysis

Experiments were run in triplicate using three different lots of samples. Data were subjected to analysis of variance (ANOVA). Comparison of means was carried out by Duncan's multiple range test at a significant level $(p<0.05)$. For the design with interactions, a complete factorial experimental design was applied (Armenta and Guerrero-Legarreta 2009). Statistical analysis was performed using the Statistical Package for Social Science (SPSS for windows, SPSS Inc., Chicago, IL, USA). 


\section{Results and discussion}

Effect of different temperatures on astaxanthin degradation and lipid oxidation of shrimp oil

\section{Kinetics of astaxanthin degradation}

Astaxanthin is sensitive to oxidation because of its highly unsaturated structures. As a consequence, astaxanthin undergoes degradation during storage (Ribeiro et al. 2005). Varying astaxanthin degradations were observed at the various temperatures as shown in Table 1. The initial astaxanthin content for shrimp oil was $0.90 \pm 0.01 \mathrm{mg} / \mathrm{g}$ oils. Shrimp oil had the lowest astaxanthin degradation, in which only $0.46 \%$ of astaxanthin was oxidized after $16 \mathrm{~h}$ of incubation at $4{ }^{\circ} \mathrm{C}$. Shrimp oil incubated at 30,45 and $60{ }^{\circ} \mathrm{C}$ showed the higher percentage of astaxanthin degradation, 4.43, 10.92 and $16.51 \%$, respectively. Thus, astaxanthin contents in shrimp oil decreased with increasing storage time and temperature $(p<0.05)$. Pu et al. (2010) reported that astaxanthin in flaxseed oil stored at 30 and $40{ }^{\circ} \mathrm{C}$ was stable, whilst astaxanthin concentrations decreased when kept at 50 and $60{ }^{\circ} \mathrm{C}$. Since astaxanthin was considered as an effective antioxidant in oil (Pu et al. 2010), the degradation of astaxanthin might be associated with the lower oxidative stability of fatty acids and cholesterol in oil (Becerra et al. 2014). Due to the high content of PUFAs of shrimp oil, lipid oxidation could take place with ease, leading to the formation of highly reactive species, such as alkyl and peroxyl radicals, etc. Those species could increase the degradation of easily oxidisable compounds such as carotenoid (Lavecchia and Zuorro 2008).

Thermal degradation of astaxanthin has been studied in several model systems (Niamnuy et al. 2008). Astaxanthin degradation in oil from hepatopancreas of Pacific white shrimp at various temperatures was described as the first order kinetics as evidenced by linearity of plot between $\ln \left(C / C^{\prime}\right)$ of astaxanthin and time (h) (Fig. 1). The rate constant $(k)$ of astaxanthin degradation was determined by linear regression of $\ln \left(C / C^{\prime}\right)$ against time. The first-order kinetics demonstrated that the $k$ of astaxanthin degradation in shrimp oil increased with increasing storage temperature $(p<0.05)$ (Table 1), indicating that astaxanthin was degraded at a faster rate at a higher temperature. The $k$ values for shrimp oil stored at $4,30,45$ and $60{ }^{\circ} \mathrm{C}$ were $0.03 \times 10^{-2}$, $0.29 \times 10^{-2}, 0.79 \times 10^{-2}$ and $1.19 \times 10^{-2} \mathrm{~h}^{-1}$, respectively. The $R^{2}$ of the first-order kinetics model were $0.93,0.96,0.94$ and 0.96 for samples stored at $4,30,45$ and $60{ }^{\circ} \mathrm{C}$, respectively (Table 1). The results indicated that the first-order kinetics could be used to describe the astaxanthin degradation in shrimp oil samples kept at temperatures between 4 and $60{ }^{\circ} \mathrm{C}$. Pu and Sathivel (2011) reported that the degradation of astaxanthin in flaxseed oil containing crawfish astaxanthin was described by the first-order reaction kinetics. Rao et al. (2007) also reported drastic reductions in astaxanthin concentrations at elevated heat processing temperatures.

The Arrhenius plot of $\ln (k)$ versus $1 / T$ for astaxanthin degradation of shrimp oil is presented in Fig. 2. The slope corresponds to the activation energy $\left(E_{\mathrm{a}}\right)$ divided by the molar gas constant. The $k$ values of shrimp oil was well described by the Arrhenius equation, in which a high $R^{2}(0.9821)$ was obtained. The activation energy $\left(E_{\mathrm{a}}\right)$ of astaxanthin degradation in shrimp oil was $52.01 \mathrm{~kJ} / \mathrm{mol}$, which was lower than that previously reported for carotenoids degradation in flaxseed oil containing astaxanthin during heat treatment $\left(E_{\mathrm{a}}=88.44 \mathrm{~kg} / \mathrm{mol}\right)\left(\mathrm{Pu}\right.$ et al. 2010). $E_{\mathrm{a}}$ is the least amount of energy that must be overcome for a chemical

Table 1 Kinetics of astaxanthin degradation in shrimp oil

\begin{tabular}{|c|c|c|c|c|}
\hline Temperature $\left({ }^{\circ} \mathrm{C}\right)$ & $k \times 10^{-2}\left(\mathrm{~h}^{-1}\right)$ & $R^{2}$ & $t_{1 / 2}(\mathrm{~h})$ & Astaxanthin degradation (\%) \\
\hline $4{ }^{\circ} \mathrm{C}$ & $0.03 \pm 0.01^{\mathrm{d}}$ & 0.9314 & $2,888 \pm 816.88^{\mathrm{a}}$ & $0.46 \pm 0.09^{\mathrm{d}}$ \\
\hline $30{ }^{\circ} \mathrm{C}$ & $0.29 \pm 0.02^{\mathrm{c}}$ & 0.9554 & $299 \pm 27.76^{b}$ & $4.43 \pm 1.80^{\mathrm{c}}$ \\
\hline $45^{\circ} \mathrm{C}$ & $0.79 \pm 0.04^{\mathrm{b}}$ & 0.9417 & $91 \pm 4.18^{\mathrm{b}}$ & $10.92 \pm 0.72^{\mathrm{b}}$ \\
\hline $60{ }^{\circ} \mathrm{C}$ & $1.19 \pm 0.04^{\mathrm{a}}$ & 0.9607 & $62 \pm 2.16^{\mathrm{b}}$ & $16.51 \pm 1.62^{\mathrm{a}}$ \\
\hline $\mathrm{Ea}(\mathrm{kJ} / \mathrm{mol})$ & $52.01 \pm 5.08$ & & & \\
\hline
\end{tabular}

Data are expressed as mean $\pm \mathrm{SD}(n=3)$

Different lowercase superscripts in the same column indicate significant differences $(p<0.05)$

$k$ rate constant, $t_{1 / 2}$ half-life, $E a$ activation energy 


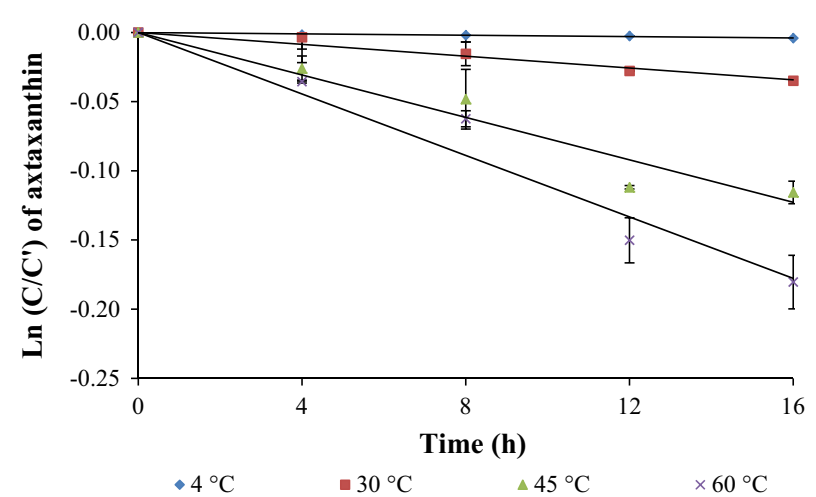

Fig. 1 The first-order kinetic plots of astaxanthin degradation in shrimp oil at various temperatures. $C$ is the concentration of astaxanthin at time, $C^{\prime}$ is the initial concentration of astaxanthin. Bars represent standard deviations $(n=3)$

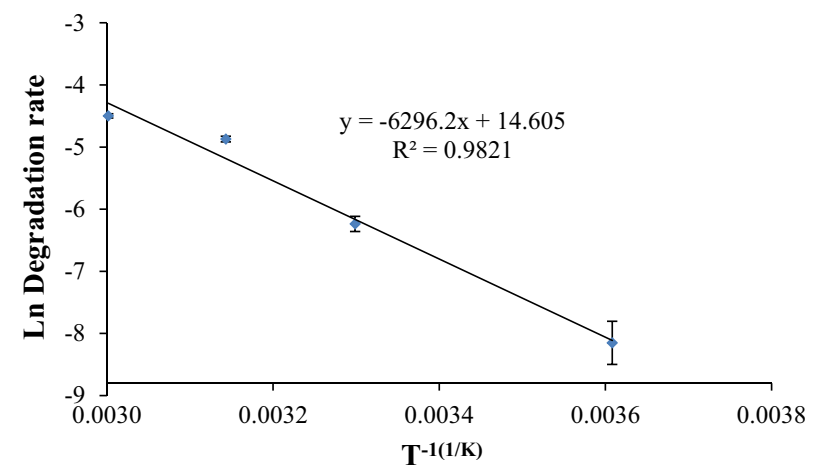

Fig. 2 The Arrhenius plot for the astaxanthin degradation of shrimp oil. Bars represent standard deviations $(n=3)$

reaction to occur (Farhoosh and Hoseini-Yazdi 2014). A chemical reaction occurs when sufficient energy is present in one or more molecules to produce rupture or formation of covalent bonds amongst atoms of these molecules when they are in proximity (Toledo 2007). To assess the storage stability of astaxanthin in shrimp oil, their apparent half-life was determined. Half-lives of shrimp oil stored at $4,30,45$ and $60{ }^{\circ} \mathrm{C}$ were 2888 , 299, 91 and $62 \mathrm{~h}$, respectively. The results indicated that the storage life or shelf-life of astaxanthin in shrimp oil was directly governed by temperatures.

\section{Kinetics of lipid oxidation}

Changes in PV of shrimp oil stored at different temperatures as a function of time are presented in Fig. 3. Hydroperoxides are the primary products of lipid oxidation and a classic indicator for quantification of oxidative rancidity (Bakkalbaş1 et al. 2012). PV mainly represents the amount of hydroperoxides formed during lipid oxidation and is usually used to evaluate the primary oxidation degree of oil (Teets and Were 2008). PV increased with increasing incubation time and temperature. The continuous increase in PV was observed at all incubation temperatures throughout $16 \mathrm{~h}$ of incubation. Nevertheless, PV slightly increased within the first $4 \mathrm{~h}$ of incubation at $4{ }^{\circ} \mathrm{C}(p<0.05)$. Thereafter, no difference in PV of shrimp oil was obtained during 4 and $16 \mathrm{~h}$ of incubation $(p>0.05)$. Generally, shrimp oil incubated at $4{ }^{\circ} \mathrm{C}$ exhibited the lowest $\mathrm{PV}$, whereas that incubated at $60{ }^{\circ} \mathrm{C}$ showed higher $\mathrm{PV}$, compared with others, for all incubation times $(p<0.05)$. The result indicated that increasing incubation time and temperature could accelerate the formation of hydroperoxides. Thus, the shrimp oil incubated at lower temperature $\left(4{ }^{\circ} \mathrm{C}\right)$ was more stable than that kept at higher temperatures $\left(30,45\right.$ and $\left.60^{\circ} \mathrm{C}\right)$.

The kinetic behaviour of the primary oxidation products is presumably zero order (Gómez-Alonso et al. 2004). The oxidation rate is dependent on several factors including temperature, the presence of inhibitors or 
catalysts, the nature of the reaction environment and compounds (Min and Boff 2002). At low or moderate temperature, the formation of oxidation compounds during the induction period is slow. At high temperature, the formation of new compounds is very rapid (Velasco and Dobarganes 2002). Additionally, the lipid oxidation at low and high temperatures may go through different steps or reaction pathways (Tan et al. 2001). The temperature also affects the degree of oxygen solubility in vegetable oils. The solubility of oxygen decreases by almost $25 \%$ for each $10{ }^{\circ} \mathrm{C}$ rise in temperature (Robertson 2000). Therefore, the results of such predictions may lead to uncertainties and errors, and can only be considered as approximate values (Farhoosh et al. 2008). The $\mathrm{k}$ of lipid oxidation for shrimp oil incubated for $16 \mathrm{~h}$ increased from 1.08 to 5.12 when temperature increased from 4 to $60{ }^{\circ} \mathrm{C}$ (Table 2).

Arrhenius plot for PV of shrimp oil is shown in Fig. 4. Regression analysis indicated that the hydroperoxide formation rate in shrimp oil increased with increasing temperature as indicated by a high $R^{2}$ value $(0.9863)$

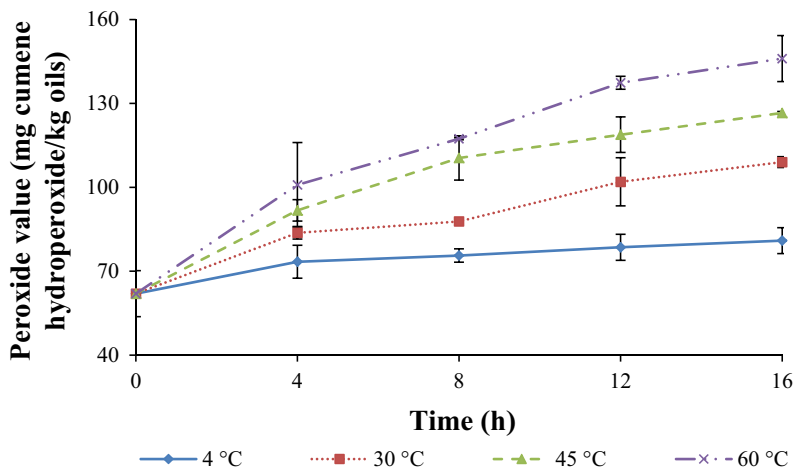

Fig. 3 Peroxide values of shrimp oil during the incubation at different temperatures. Bars represent standard deviations $(n=3)$

Table 2 Kinetics of lipid oxidation in shrimp oil

\begin{tabular}{llr}
\hline Temperature $\left({ }^{\circ} \mathrm{C}\right)$ & $k\left(\mathrm{~h}^{-1}\right)$ & $R^{2}$ \\
\hline 4 & $1.08 \pm 0.11^{\mathrm{d}}$ & 0.8582 \\
30 & $2.81 \pm 0.10^{\mathrm{c}}$ & 0.9497 \\
45 & $3.91 \pm 0.45^{\mathrm{b}}$ & 0.9160 \\
60 & $5.12 \pm 0.30^{\mathrm{a}}$ & 0.9398 \\
Ea $(\mathrm{kJ} / \mathrm{mol})$ & $21.59 \pm 0.96$ & \\
\hline
\end{tabular}

Data are expressed as mean $\pm \mathrm{SD}(n=3)$

Different lowercase superscripts in the same column indicate significant differences $(p<0.05)$

$k$ rate constant, $E a$ activation energy



Fig. 4 The Arrhenius plot for the peroxide values of shrimp oil. Bars represent standard deviations $(n=3)$ 
obtained. $E_{\mathrm{a}}$ of lipid oxidation in shrimp oil was $21.59 \mathrm{~kJ} / \mathrm{mol}$, which was lower than that previously reported $(33.2 \mathrm{~kJ} / \mathrm{mol})$ for lipid oxidation in the unrefined pollock oil (Sathivel et al. 2008). The $\mathrm{k}$ value increased as the temperature increased. Takeungwongtrakul et al. (2012) reported that shrimp oils consisted of $28.51 \%$ saturated fatty acids (SAT), $29.95 \%$ monounsaturated fatty acids (MUFA) and $37.42 \%$ PUFA. Adhvaryu et al. (2000) showed that a high PUFA content would lower the $E_{\mathrm{a}}$ value for lipid oxidation. PUFAs are more susceptible to radical-initiated triplet oxygen oxidation than MUFA. The lower $E_{\mathrm{a}}$ in the initiation of freeradical formation in PUFA was reported, compared to that of MUFA (Lea 1952).

Oxidative stability of shrimp oil as influenced by various storage conditions

\section{Changes in astaxanthin in shrimp oil}

Astaxanthin is sensitive to photodegradation (Niamnuy et al. 2008); nevertheless other variables such as temperature and oxygen availability also have the effect on its degradation during storage (Christophersen et al. 1991). Astaxanthin contents of shrimp oils stored under different conditions during 40 days of storage are presented in Table 3. Astaxanthin contents in all shrimp oil samples decreased throughout 40 days of storage $(p<0.05)$. However, astaxanthin contents in shrimp oil varied with storage conditions.

When comparing astaxanthin contents of all samples, the sample exposed to 'light + air' at $30{ }^{\circ} \mathrm{C}$ (35.27-40.53\% degradation) had the highest astaxanthin degradation after 40 days of storage $(p<0.05)$. The result was in accordance with Armenta and Guerrero-Legarreta (2009) who reported that the combination of full light, oxygen (air) and high temperature $\left(45^{\circ} \mathrm{C}\right)$ caused the pronounced oxidation of astaxanthin. This result indicated that the combination of light, air and high temperature should be avoided during storage. The concentration of astaxanthin was decreased by 22.87 and $17.33 \%$ for the samples exposed to 'dark + air' at $30{ }^{\circ} \mathrm{C}$ and 'light + nitrogen' at $30^{\circ} \mathrm{C}$, respectively after 40 days of storage. Nevertheless, the samples with 'light + nitrogen' at $30{ }^{\circ} \mathrm{C}$, 'light + air' at $4{ }^{\circ} \mathrm{C}$, 'light + nitrogen' at $4{ }^{\circ} \mathrm{C}$, 'dark + nitrogen' at $30{ }^{\circ} \mathrm{C}$ and 'dark + air' at $4{ }^{\circ} \mathrm{C}$ had no difference in astaxanthin degradation after storage $(p>0.05)$. In addition, astaxanthin degradation in samples with 'dark + air' at $4{ }^{\circ} \mathrm{C}$, 'dark + nitrogen' at $30{ }^{\circ} \mathrm{C}$ and 'light + nitrogen' at $4{ }^{\circ} \mathrm{C}$ was similar to the sample with 'dark + nitrogen' at $4{ }^{\circ} \mathrm{C}(p>0.05)$. Minimal astaxanthin degradation $(8.8 \%)$ was observed when samples were stored in the dark under nitrogen atmosphere at low temperature $\left(4^{\circ} \mathrm{C}\right)$ after 40 days of storage. The result indicated that the absence of light and oxygen in combination with low temperature was the best condition to enhance the stability of astaxanthin in shrimp oil. Nevertheless, the exclusion of light, oxygen and high temperature in food products during processing and storage may not be practical.

These results indicated that the individual factor (illumination, oxygen availability and temperature) had the effect on degradation of astaxanthin in shrimp oils $(p<0.05)$. When the factor interactions were elucidated, only the interaction between illumination and temperature was significant $(p<0.05)$. The exposure to light in combination with high temperature seemed to make a significant synergistic contribution to the increase in astaxanthin degradation $(p<0.05)$. Anarjan and Tan (2013) reported that the $k$ value of astaxanthin degradation was dependent on temperature, atmosphere and illumination conditions. Increasing storage temperature or light intensity increased the $k$ value of loss of astaxanthin nanodispersion. Polyene structure of carotenoid provides them with valuable antioxidant properties; but also causes the compounds to be easily degraded in the presence of light and/or heat (Handelman et al. 1991; Minguez-Mosquera and Jaren-Galan 1995). The bleaching of carotenoids is mediated by photooxidation and autooxidation (Boon et al. 2010; Pérez-Gálvez et al. 2005). Carotenoid oxidation mechanism is similar to the lipid oxidation. It is accelerated by heat, and the reaction is catalyzed by the presence of oxygen and light (Ishiwatari 1980). Zeb and Murkovic (2011) revealed that astaxanthin and $\beta$-carotene were found to significantly increase the PV in olive oil. After astaxanthin underwent oxidation or degradation, the radicals generated might be involved in chain reaction of lipid oxidation. 


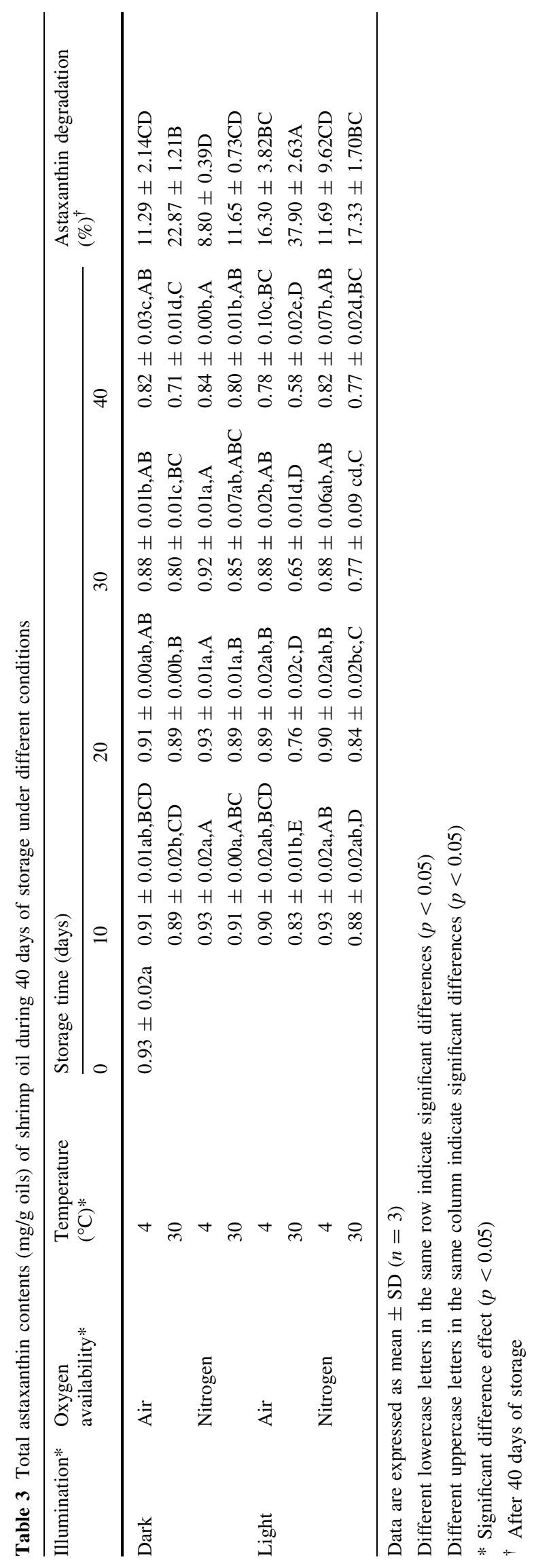


Lipid oxidation in shrimp oil

$P V$

Changes in PV of shrimp oils stored under different conditions during 40 days of storage are shown in Fig. 5a. The increase in PV of all samples indicated that the samples were in propagation stage of lipid oxidation. Lipid hydroperoxides are formed by various pathways including the reaction of singlet oxygen with unsaturated fatty acids or the lipoxygenase-catalyzed oxidation of PUFA (Nawar 1996). However, PV values varied with different storage conditions.

When comparing PV of all samples, that exposed to 'light + air' at $30{ }^{\circ} \mathrm{C}$ had the higher PV than others throughout 40 days of storage $(p<0.05)$, followed by those exposed to 'light + air' at $4{ }^{\circ} \mathrm{C}$, 'dark + air' at $30{ }^{\circ} \mathrm{C}$, 'light + nitrogen' at $30^{\circ} \mathrm{C}$, 'dark + air' at $4{ }^{\circ} \mathrm{C}$, 'light + nitrogen' at $4{ }^{\circ} \mathrm{C}$ or 'dark + nitrogen' at $30{ }^{\circ} \mathrm{C}$ and 'dark + nitrogen' at $4{ }^{\circ} \mathrm{C}$, respectively $(p<0.05)$. The lowest increase in PV after 40 days of
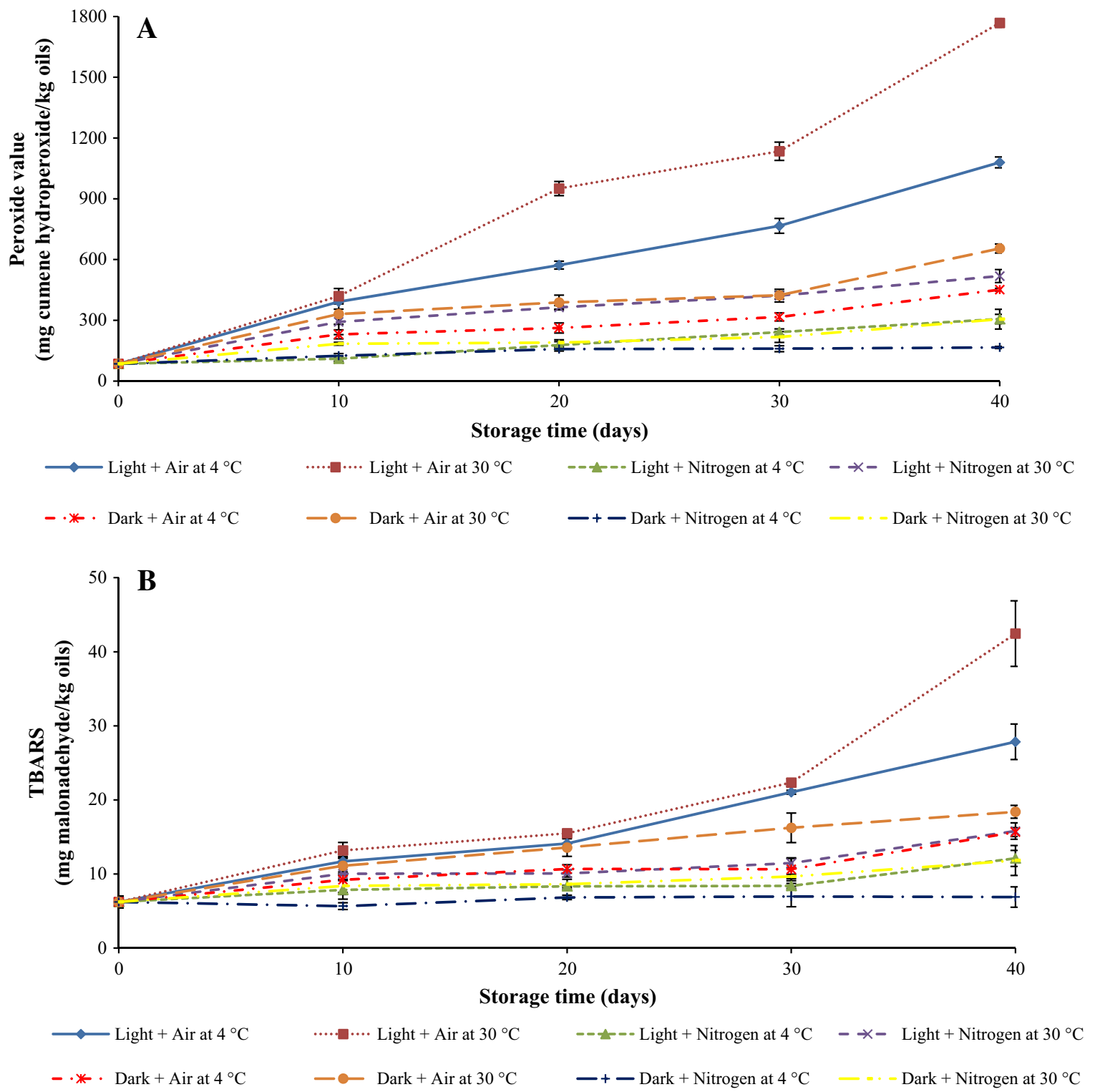

Fig. 5 Peroxide values (a) and TBARS values (b) of shrimp oil during 40 days of storage under different storage conditions. Bars represent standard deviations $(n=3)$ 
storage was observed in the sample with 'dark and nitrogen' at $4{ }^{\circ} \mathrm{C}(p<0.05)$. With the same oxygen availability and temperature, the sample kept in dark had the lower increase in PV in shrimp oil, compared with that exposed to light $(p<0.05)$. Schaich et al. (2013) reported that visible light lacks the energy to produce radicals directly, but it can initiate lipid oxidation indirectly through photosensitisers that absorb lowlevel light energy, and transform it to chemical energy sufficient to drive reactions. Within the same illumination and temperature, the sample stored under nitrogen atmosphere had a lower PV than that stored in air $(p<0.05)$. Oxygen in air is a primary reactant in lipid oxidation which fuels the fatty acid decomposition pathway that causes rancidity (Chen et al. 2011). The removal of oxygen from extra virgin olive oil by nitrogen purging lowered PV (Masella et al. 2010). The sample stored at $4{ }^{\circ} \mathrm{C}$ showed the higher oxidative stability than that stored at $30^{\circ} \mathrm{C}$ when the same oxygen availability and illumination were used $(p<0.05)$. Autoxidation, which proceeds once the initial free radicals are formed, is affected by temperature (Andersen et al. 2006). During storage at low temperature, the oxidation processes are retarded but not stopped. In fact, some oil-soluble radicals may even be more stable at lower temperatures, thereby propagating the oxidation (Kanner 1994).

These results indicated that the individual factor (illumination, oxygen availability and temperature) had the influence on PV in shrimp oils $(p<0.05)$. When considering factor interactions, only the interaction between illumination and oxygen availability was significant $(p<0.05)$. The exposure to light in combination with oxygen seemed to make a significant synergistic contribution to the enhanced lipid oxidation. Lipid oxidation can occur through autoxidation or photo-oxidation. Thus, shrimp oil in the presence of light or air could have the accelerated formation of hydroperoxide with decreased stability, especially when stored at high temperature.

\section{TBARS}

Changes in TBARS of shrimp oils stored under different conditions during 40 days of storage are given in Fig. 5b. TBARS value of all samples increased during 40 days of storage $(p<0.05)$. Changes in TBARS values showed a similar trend with PV. Oils were more likely oxidized and hydroperoxides were subsequently decomposed into the secondary products, including malonaldehyde (MDA) and other carbonyl compounds during storage (Ganhão et al. 2011).

When comparing TBARS values of all samples, shrimp oil exposed to 'light + air' at $30{ }^{\circ} \mathrm{C}$ showed the highest TBARS value throughout 40 days of storage, followed by those exposed to 'light + air' at $4{ }^{\circ} \mathrm{C}$ and 'dark + air' at $30^{\circ} \mathrm{C}$, respectively $(p<0.05)$. Shrimp oil stored with 'light + nitrogen' at $4{ }^{\circ} \mathrm{C}$ and 'dark + nitrogen' at $30^{\circ} \mathrm{C}$ showed no differences in TBARS values after 40 days $(p>0.05)$. Shrimp oil stored in 'light + nitrogen' at $30{ }^{\circ} \mathrm{C}$ had the similar TBARS value to that stored in 'dark + air' at $4{ }^{\circ} \mathrm{C}$ during the storage $(p>0.05)$. At the end of storage (40 days), the lowest TBARS value was obtained in the sample with 'dark + nitrogen' at $4{ }^{\circ} \mathrm{C}(p<0.05)$. These results indicated that lowering illumination, oxygen availability and temperature led to the lower TBARS values. According to the results of Pristouri et al. (2010), the exposure of olive oil samples to light, high storage temperatures and large headspace volumes caused the substantial deterioration in product. The most pronounced effects were temperature and light, whilst the smallest effects were headspace volume and packaging material permeability to oxygen (Pristouri et al. 2010).

These results indicated that the individual factor (illumination, oxygen availability and temperature) had the effect on TBARS values in shrimp oils $(p<0.05)$. Illumination showed the interaction with oxygen availability in enhancing lipid oxidation process. Thus, the exposure of packaged shrimp oil to light, air or heat should be avoided since it could stimulate the oxidation of shrimp oil.

\section{Conclusion}

Astaxanthin degradation and lipid oxidation in shrimp oil increased with increasing incubation temperature. Astaxanthin degradation and lipid oxidation of the shrimp oil as a function of temperature could be well described by the Arrhenius equation. Oxidative stability of shrimp oil varied with different storage conditions during storage for 40 days. All individual factors such as oxygen available, light and temperature had the effect on astaxanthin degradation and lipid oxidation in shrimp oils. However, light and air were found to 
show the interaction on astaxanthin degradation and lipid oxidation of shrimp oil during the storage. Thus, the best storage condition of shrimp oil was the dark and nitrogen atmosphere at low temperature $\left(4^{\circ} \mathrm{C}\right)$. The storage of shrimp oil with light under air atmosphere at higher temperature was found as the worse condition.

Authors' contributions SB initiated the idea and designed the study. ST was responsible for conducting the experiments and analysis of data. SB and ST carried out the analytical work. ST wrote the manuscript with asssitance from SB. SB read and approved the final manuscript.

Acknowledgments This research was also supported by the Postdoctoral Fellowship from Prince of Songkla. Agricultural Research Development Agency and the TRF Distinguished Research Professor Grant were also acknowledged.

Open Access This article is distributed under the terms of the Creative Commons Attribution 4.0 International License (http:// creativecommons.org/licenses/by/4.0/), which permits unrestricted use, distribution, and reproduction in any medium, provided you give appropriate credit to the original author(s) and the source, provide a link to the Creative Commons license, and indicate if changes were made.

\section{References}

Adhvaryu A, Erhan S, Liu Z, Perez J (2000) Oxidation kinetic studies of oils derived from unmodified and genetically modified vegetables using pressurized differential scanning calorimetry and nuclear magnetic resonance spectroscopy. Thermochim Acta 364:87-97

Aidos I, Lourenclo S, Avd Padt, Luten J, Boom R (2002) Stability of crude herring oil produced from fresh byproducts: influence of temperature during storage. J Food Sci 67:3314-3320

Anarjan N, Tan CP (2013) Effects of storage temperature, atmosphere and light on chemical stability of astaxanthin nanodispersions. J Am Oil Chem Soc 90:1223-1227

Andersen CM, Wold JP, Mortensen G (2006) Light-induced changes in semi-hard cheese determined by fluorescence spectroscopy and chemometrics. Int Dairy J 16:1483-1489

Armenta RE, Guerrero-Legarreta I (2009) Stability studies on astaxanthin extracted from fermented shrimp byproducts. J Agric Food Chem 57:6095-6100

Bakkalbaşı E, Yılmaz ÖM, Javidipour I, Artık N (2012) Effects of packaging materials, storage conditions and variety on oxidative stability of shelled walnuts. LWT-Food Sci Technol. 46:203-209

Becerra JAH, Flores AAO, Valerio-Alfaro G, Soto-Rodriguez I, Rodríguez-Estrada MT, García HS (2014) Cholesterol oxidation and astaxanthin degradation in shrimp during sun drying and storage. Food Chem 145:832-839

Boon CS, McClements DJ, Weiss J, Decker EA (2010) Factors influencing the chemical stability of carotenoids in foods. Crit Rev Food Sci Nutr 50:515-532

Borsarelli CD, Mercadante AZ (2010) Thermal and photochemical degradation of carotenoids. In: Landrum JT (ed) Carotenoids: physical, chemical, and biological functions and properties. CRC Press, Boca Raton, pp 229-253

Buege JA, Aust SD (1978) Microsomal lipid peroxidation. Method Enzymol. 52:302-310

Chaijan M, Benjakul S, Visessanguan W, Faustman C (2006) Changes of lipids in sardine (Sardinella gibbosa) muscle during iced storage. Food Chem 99:83-91

Chen B, McClements DJ, Decker EA (2011) Minor components in food oils: a critical review of their roles on lipid oxidation chemistry in bulk oils and emulsions. Crit Rev Food Sci Nutr 51:901-916

Christophersen AG, Jun H, Jørgensen K, Skibsted LH (1991) Photobleaching of astaxanthin and canthaxanthin. Z Lebensm Unters For 192:433-439

Erkan N, Ayranci G, Ayranci E (2009) A kinetic study of oxidation development in sunflower oil under microwave heating: effect of natural antioxidants. Food Res Int 42:1171-1177

FAO (2015) Food and Agriculture Organization of the United Nations. Information Service, Data and Statistics Fisheries. FISHSTAT Plus. Universal Software for Fishery Statistical Time Series, Roma. http://www.fao.org/fishery/statistics/ software/fishstat/en. Accessed 20 Dec 2015

Farhoosh R, Hoseini-Yazdi S-Z (2014) Evolution of oxidative values during kinetic studies on olive oil oxidation in the Rancimat test. J Am Oil Chem Soc 91:281-293

Farhoosh R, Niazmand R, Rezaei M, Sarabi M (2008) Kinetic parameter determination of vegetable oil oxidation under Rancimat test conditions. Eur J Lipid Sci Technol 110:587-592

Ganhão R, Estévez M, Morcuende D (2011) Suitability of the TBA method for assessing lipid oxidation in a meat system with added phenolic-rich materials. Food Chem 126:772-778

Gómez-Alonso S, Mancebo-Campos V, Desamparados Salvador M, Fregapane G (2004) Oxidation kinetics in olive oil triacylglycerols under accelerated shelf-life testing $\left(25-75^{\circ} \mathrm{C}\right)$. Eur J Lipid Sci Technol 106:369-375

Handelman GJ, van Kuijk FJ, Chatterjee A, Krinsky NI (1991) Characterization of products formed during the autoxidation of $\beta$ carotene. Free Radical Bio Med. 10:427-437

Huang J, Sathivel S (2008) Thermal and rheological properties and the effects of temperature on the viscosity and oxidation rate of unpurified salmon oil. J Food Eng 89:105-111

Ishiwatari M (1980) Thermal reaction of $\beta$-carotene. Part 1. J Anal Appl Pyrol 2:153-167

Kanner J (1994) Oxidative processes in meat and meat products: quality implications. Meat Sci 36:169-189 
Lavecchia R, Zuorro A (2008) Shelf stability of lutein from marigold (Tagetes erecta L.) flowers in vegetable oils. Chem Eng Trans 14:199-204

Lea C (1952) Methods for determining peroxide in lipids. J Sci Food Agric 3:586-594

Mancebo-Campos V, Fregapane G, Desamparados Salvador M (2008) Kinetic study for the development of an accelerated oxidative stability test to estimate virgin olive oil potential shelf life. Eur J Lipid Sci Technol 110:969-976

Masella P, Parenti A, Spugnoli P, Calamai L (2010) Nitrogen stripping to remove dissolved oxygen from extra virgin olive oil. Eur J Lipid Sci Technol 112:1389-1392

Min D, Boff J (2002) Chemistry and reaction of singlet oxygen in foods. Compr Rev Food Sci Food Saf. 1:58-72

Minguez-Mosquera MI, Jaren-Galan M (1995) Kinetics of the decolouring of carotenoid pigments. J Sci Food Agric 67:153-161

Nawar WW (1996) Lipids. In: Fennema OR (ed) Food chemistry. Marcel Dekker Inc, New York, pp 225-314

Niamnuy C, Devahastin S, Soponronnarit S, Vijaya Raghavan G (2008) Kinetics of astaxanthin degradation and color changes of dried shrimp during storage. J Food Eng 87:591-600

Pérez-Gálvez A, Rios JJ, Mínguez-Mosquera MI (2005) Thermal degradation products formed from carotenoids during a heatinduced degradation process of paprika oleoresins (Capsicum annиum L.). J Agric Food Chem 53:4820-4826

Pristouri G, Badeka A, Kontominas M (2010) Effect of packaging material headspace, oxygen and light transmission, temperature and storage time on quality characteristics of extra virgin olive oil. Food Control 21:412-418

Pu J, Sathivel S (2011) Kinetics of lipid oxidation and degradation of flaxseed oil containing crawfish (Procambarus clarkii) astaxanthin. J Am Oil Chem Soc 88:595-601

Pu J, Bechtel PJ, Sathivel S (2010) Extraction of shrimp astaxanthin with flaxseed oil: effects on lipid oxidation and astaxanthin degradation rates. Biosyst Eng 107:364-371

Rao AR, Sarada R, Ravishankar GA (2007) Stabilization of astaxanthin in edible oils and its use as an antioxidant. J Sci Food Agric 87:957-965

Ribeiro HS, Rico LG, Badolato GG, Schubert H (2005) Production of O/W emulsions containing astaxanthin by repeated premix membrane emulsification. J Food Sci 70:E117-E123

Robertson GL (2000) Shelf life of packaged foods, its measurements and prediction. In: Brody AL (ed) Developing new food products for a changing marketplace. Technomic Publishing, UK, pp 329-353

Saito A, Regier L (1971) Pigmentation of brook trout (Salvelinus fontinalis) by feeding dried crustacean waste. J. Fish. Board Can. 28:509-512

Sathivel S, Huang J, Prinyawiwatkul W (2008) Thermal properties and applications of the Arrhenius equation for evaluating viscosity and oxidation rates of unrefined pollock oil. J Food Eng 84:187-193

Schaich K, Shahidi F, Zhong Y, Eskin N (2013) Lipid oxidation. In: Eskin N (ed) Biochemistry of foods. Academic Press, London, pp 419-478

Takeungwongtrakul S, Benjakul S, H-kittikun A (2012) Lipids from cephalothorax and hepatopancreas of Pacific white shrimp (Litopenaeus vannamei): compositions and deterioration as affected by iced storage. Food Chem 134:2066-2074

Takeungwongtrakul S, Benjakul S, Santoso J, Trilaksani W, Nurilmala M (2014) Extraction and stability of carotenoid-containing lipids from hepatopancreas of Pacific white shrimp (Litopenaeus vannamei). J Food Process Pres. 39:10-18

Tan C, Man YC, Selamat J, Yusoff M (2001) Application of Arrhenius kinetics to evaluate oxidative stability in vegetable oils by isothermal differential scanning calorimetry. J Am Oil Chem Soc 78:1133-1138

Teets AS, Were LM (2008) Inhibition of lipid oxidation in refrigerated and frozen salted raw minced chicken breasts with electron beam irradiated almond skin powder. Meat Sci 80:1326-1332

Toledo RT (2007) Kinetics of chemical reactions in foods. Fundamentals of food process engineering, 3rd edn. New York: Springer, pp 285-299

Velasco J, Dobarganes C (2002) Oxidative stability of virgin olive oil. Eur J Lipid Sci Technol 104:661-676

Zeb A, Murkovic M (2011) Carotenoids and triacylglycerols interactions during thermal oxidation of refined olive oil. Food Chem 127:1584-1593 